\title{
ANÁLISE DO DISCURSO E ENSINO: A TEORIA ENTRE PRÁTICAS E POLÍTICAS
}

\section{DISCOURSE ANALYSIS AND TEACHING: THE THEORY BETWEEN PRACTICES AND POLICIES}

\author{
Andréa Rodrigues ${ }^{1}$, Maristela Cury Sarian ${ }^{2}$, Rívia Silveira Fonseca ${ }^{3}$ \\ ${ }^{1}$ Universidade do Estado do Rio de Janeiro (UERJ), São Gonçalo, RJ, Brasil \\ andrearodrigues.letras@gmail.com \\ ${ }^{2}$ Universidade do Estado de Mato Grosso (UNEMAT), Cáceres, MT, Brasil \\ maristelasarian@unemat.br \\ ${ }^{3}$ Universidade Federal Rural do Rio de Janeiro (UFRRJ), Seropédica, RJ, Brasil \\ riviafonseca@gmail.com
}

É com satisfação que apresentamos, neste número da Pensares em Revista, o Dossiê Análise de Discurso e Ensino: a teoria entre práticas e políticas, com trabalhos que pensam o ensino no quadro teórico da Análise de Discurso (AD) inaugurada na França por Michel Pêcheux e, no Brasil, desenvolvida por Eni Orlandi e demais pesquisadores.

No Dossiê estão reunidos três entrevistas e onze artigos. A seção de abertura, dedicada às entrevistas, procurou colocar em evidência a relação Análise de Discurso e Ensino na voz de três pesquisadoras de referência para os estudos da AD e da História das Ideias Linguísticas (HIL) no Brasil: Eni Orlandi, Freda Indursky e Vanise Medeiros.

A entrevista com Eni Orlandi, assinada por Maristela Sarian, gravitou em torno do funcionamento do discurso pedagógico na contemporaneidade, a formação dos profissionais das Letras e seus efeitos na educação básica e superior, a partir de compreensões de Orlandi sobre os sentidos de leitura, escrita e tecnologias em circulação no espaço simbólico, material e social do urbano, imprimindo uma sua relação entre a escola, a universidade e a cidade.

$\mathrm{Na}$ entrevista com Freda Indursky, proposta por Andréa Rodrigues, a entrevistada nos apresenta reflexões sobre a prática de leitura na escola, as possibilidades de interpretação das chamadas fake news, o modo como a AD poderia estar nos cursos de Letras, a AD na França atual e os caminhos que os professores podem seguir hoje em tempos tão sombrios, sem abrir mão de práticas reflexivas de leitura.

Vanise Medeiros, entrevistada por Rívia Fonseca, destaca o lugar que a AD e os estudos em HIL podem ocupar na prática docente e aponta como exemplo o 
trabalho com glossários e dicionários em aulas de língua portuguesa, nos cursos de graduação em Letras, como ponto de partida para uma reflexão sobre a opacidade da língua. A entrevistada reflete ainda sobre os problemas relativos ao discurso pedagógico e seu funcionamento diante do cenário político-histórico atual.

$\mathrm{Na}$ segunda seção, dedicada aos artigos do Dossiê, três grandes eixos direcionam a sequência de apresentação dos textos, que dão visibilidade:

1 - a políticas de ensino de línguas, materializadas em campanhas governamentais e em propostas curriculares de redes públicas de ensino e de formação de professores;

2 - ao funcionamento do discurso pedagógico na contemporaneidade e suas possibilidades de ressignificação; e

3 - as práticas de ensino da leitura que colocam em evidência o desenvolvimento de projetos realizados na educação básica e na universidade.

Nessa direção, em Sentidos de direitos de aprendizagem e cidadania em documentos curriculares oficiais: discurso, ensino e subjetividade, Marisa Grigoletto e Laura Fortes investigam o discurso político-educacional em circulação em políticas públicas de ensino para a educação básica no Brasil na última década, com foco no ensino de língua inglesa, a partir de documentos de orientação curricular da Secretaria Municipal de Educação de São Paulo, produzidos entre 2015 e 2019. Com o objetivo de compreenderem o funcionamento de sentidos produzidos para o ensino e suas implicações históricas, ideológicas e políticas, apontam os sentidos voltados à aprendizagem como direito e à cidadania como objetivo final da formação escolar, o que coloca em evidência um predomínio da forma-sujeito jurídica sobre outras subjetividades possíveis, constituindo-se como promessa de obtenção, por parte do aprendiz, de uma "cidadania global".

Em As políticas de alfabetização dos governos FHC (1995-2002) e Lula (2003-2010): “Alfabetização Solidária” e "Brasil Alfabetizado”, Bethania Sampaio Corrêa Mariani, Fernanda Gonçalves de Laia e Tatiana Freire de Moura propõem uma reflexão sobre políticas públicas voltadas para a educação, especialmente, para a alfabetização de jovens e adultos, nos governos dos ex-presidentes Fernando Henrique Cardoso (FHC) e Luiz Inácio Lula da Silva (Lula) a partir de um corpus composto por duas propagandas de alfabetização que circularam nos anos de 1990 e 2000. Objetiva-se compreender o funcionamento discursivo dessas duas políticas 
públicas nacionais de combate ao analfabetismo que caracterizaram dois governos do Brasil, em diferentes condições de produção, por meio das quais se coloca em evidência as posições-sujeito projetadas para os sujeitos brasileiros jovens e/ou adultos sobre ser analfabeto ou alfabetizado e sobre seus modos de estar na sociedade brasileira e no mundo.

Abrindo um segundo eixo de discussão, que aborda o discurso pedagógico, o artigo Língua, ensino e discurso: do mesmo ao diferente, de Marilei Resmini Grantham, apresenta uma reflexão sobre ensino de língua a partir da posição sujeito professor, a fim de compreender como se produz o imaginário sobre o professor, traçando um breve panorama histórico. Para dar sustentação a sua argumentação, toma para análise três provérbios, mobilizando os conceitos de paráfrase e polissemia como forma de colocar em evidência que assumir uma perspectiva discursiva de língua e de ensino significa, para o professor, descolar-se de um discurso autoritário, que reforça o mesmo, e procurar instaurar um discurso polêmico ou lúdico, que abre espaço para o diferente.

Carolina Fernandes, em Nem autoritário, nem cínico, apenas polêmico: as formas do discurso pedagógico atual e seus processos de identificação, apresenta uma análise do funcionamento do discurso pedagógico escolar atual. O corpus de análise reúne diários de campo de observações de aulas de Língua Portuguesa produzidos por professores da rede municipal da cidade de Bagé, interior do RS, e de projetos de ensino de estágios curriculares e do Mestrado Profissional em Ensino de Línguas. A autora observa que, além da forma autoritária, o discurso pedagógico atualmente assume uma forma cínica, já que o sujeito-professor, em uma posiçãoenunciativa de especialista na área da linguagem, apropria-se das críticas ao ensino da gramática e da metalinguagem, passando a defender o ensino da leitura e produção textual, entretanto, em sua prática pedagógica, mantém a antiga metodologia, sobretudo com o ato mecânico da "cópia", trazendo como alternativa o discurso pedagógico polêmico como propulsor de novos gestos de leitura e de ensino.

Rosyane Mayre Pimenta Natal, em O efeito de indeterminação: uma discussão a partir da formação discursiva do discurso pedagógico, coloca em evidência os sentidos do efeito de indeterminação no discurso pedagógico (ORLANDI, 2006), tomando como base a noção de terceira-pessoa discursiva, proposta por Indursky 
(1992). A autora mobiliza duas sequências discursivas produzidas por dois professores, em uma situação de conversa entre a pesquisadora e os sujeitos participantes desta pesquisa. A análise coloca em evidência como a indeterminação vai produzir um efeito de apagamento do sujeito-professor nos processos de alfabetização, no momento em que expõe as dificuldades encontradas na prática alfabetizadora.

Iniciando o eixo que envolve práticas de ensino, o artigo $A$ roupa da rua: preconceito linguístico em discurso, de Soraya Maria Romano Pacífico e Michel Luís da Cruz Ramos Leandro, se propõe a interpretar o discurso de sujeitos-alunos do ensino médio, de uma escola particular de Ribeirão Preto - SP, sobre preconceito linguístico, por meio de recortes das provas escritas. Os autores destacam que os sujeitos-alunos (re)conhecem o preconceito linguístico e argumentam contra ele, embora, muitas vezes, eles se filiem à formação discursiva dominante que reforça a legitimidade de uma língua dita correta, apontando para uma prática de ensino de língua que coloca em funcionamento as variedades linguísticas, de modo a desnaturalizar a visão reducionista e preconceituosa de língua ideal.

Helson Flávio da Silva Sobrinho, em $A$ leitura política da palavra: uma experiência didática, teórica e também política, apresenta resultados de uma atividade de leitura-interpretação produzida em uma universidade, estendida a outros grupos de sujeitos fora do espaço universitário. $O$ autor propõe uma reflexão teórica e política sobre essa experiência/vivência educativa enquanto gesto político de ensino, por meio da análise da palavra "política", a partir de sua articulação com as condições históricas de produção.

Tatiana Barbosa de Sousa e Maria Cleci Venturini, em O espaço cemiterial: leituras discursivas do espaço urbano, elegem o cemitério como um lugar de memória da cidade e um objeto discursivo, a partir do qual apresentam uma proposta de leitura discursiva na escola, realizada com professores do ensino fundamental e médio, participantes do Programa de Desenvolvimento Educacional (PDE/PR). Trata-se de uma proposta de leitura do espaço urbano sustentada na contradição dada pela morte - comum a todos os sujeitos, significando a leitura como prática social e discursiva e a história da cidade como constitutiva do sujeito.

Luciana Cristina Ferreira Dias Di Raimo, em Uma proposta discursiva de leitura nas condições do PROFLETRAS: no jogo entre paráfrase e polissemia, apresenta 
uma proposta discursiva de leitura desenvolvida com mestrandos do Profletras, na disciplina "Linguagem, práticas sociais e ensino", no batimento teoria e prática. Com o objetivo de apresentar possíveis encaminhamentos para o texto e problematizar algumas questões pertinentes ao ensino da leitura de língua portuguesa, tais como a evidência dos sentidos, a contradição e a equivocidade, mostra como foram criadas as condições para que se tomasse a sala de aula como um evento interpretativo, um espaço de efetivação de autoria por parte de alunos e (também) de professores, movimento que produziu efeitos no seu fazer de docente.

Flávia Ferreira Santana e Maristela Cury Sarian, em Gestos de leitura e escrita discursiva de memes: efeitos do digital em uma escola pública do campo, colocam em evidência um processo de produção de leitura de memes, textualizados por meio de diferentes materialidades significantes, na discursividade do eletrônico. $O$ trabalho, desenvolvido sob forma de intervenção pedagógica como parte dos trabalhos desenvolvidos no Programa de Mestrado Profissional em Letras PROFLETRAS, ofertado na UNEMAT/Cáceres, mostra a produtividade de se mobilizar as noções de paráfrase e polissemia, para desestabilizar os sentidos que circulam como evidentes sobre leitura, escrita e TICs na escola, a partir da entrada das discursividades contemporâneo-digitais, em seu caráter material, significadas como uma possibilidade de ressignificar o ensino-aprendizagem de língua portuguesa.

Andréa Rodrigues, Marcos André de Oliveira Moraes e Mariana Vieira Domingues, em $O$ impacto da análise do discurso em práticas de ensino: experiências com leitura e escrita na escola, apresentam o desenvolvimento de dois projetos que se propuseram a promover práticas de leitura e escrita na escola com base no aporte teórico-metodológico da AD. As experiências de ensino foram realizadas com alunos do ensino fundamental em duas escolas públicas - rede municipal das cidades de Maricá e de Duque de Caxias, no Estado do Rio de Janeiro. Os autores apontam as contribuições que noções como as de leitura, escrita e autoria podem trazer para as práticas docentes e, consequentemente, para as atividades de leitura e escrita realizadas na escola.

Fechando o volume, há três artigos na seção Varia que também envolvem o debate sobre o ensino, apresentando reflexões a partir de experiências em diferentes lugares - França, Brasil, Marrocos -, com base em outras abordagens 
teóricas. No primeiro, Instructions officielles: quand les représentations sociales se mêlent de didactique, Marc Rollin, professor de língua espanhola na França, discute as representações sociolinguísticas e sociodidáticas em textos oficiais sobre ensino de línguas estrangeiras e regionais do Ministério da Educação Nacional francês. O autor defende que essas representações não são neutras, pois participam da transmissão de ideias e teorias sobre o ensino-aprendizagem de línguas, apoiadas ou não pela investigação. $O$ artigo se propõe, assim, a apontar algumas representações sobre o ensino de línguas vivas na França, transmitidas pelos currículos do ciclo $4\left(7^{\circ}, 8^{\circ}\right.$ e $9^{\circ}$ ano $)$ de 2015 , em conexão com outros textos.

No segundo artigo da Varia, Literatura Jovem Adulto, projeto de extensão e a democratização do conhecimento: a leitura como um direito cidadão, Martha Julia Martins de Souza apresenta os resultados de um projeto de extensão voltado para a leitura de livros em inglês do gênero YA (young adult ) em uma universidade pública federal, que se apresenta como uma prática social que integra o ensino formal de língua inglesa à democratização da leitura em língua estrangeira no Brasil. Metodologicamente, o trabalho se estrutura com base em questionários e diários de bordo dos alunos participantes, analisados sob a ótica do pensamento decolonial. A pesquisa e o projeto de extensão vão além da formação de leitores de uma língua estrangeira hegemônica, mas servem ao propósito político e pedagógico de mobilizar uma juventude cidadã que anseie por uma sociedade mais justa, igualitária e consciente dos discursos de preconceito e ódio que se manifestam na atualidade.

Finalizando a seção Varia, o artigo Intertextualité et écrite: l'apport de texte litteraire dans une experience de production écrite avec des lyceens au Maroc, de Salah Tigourdi, apresenta uma experiência com produção textual desenvolvida num liceu de Marrocos, em aulas de língua francesa, com o objetivo de demonstrar a contribuição do texto literário nas atividades de produção escrita, utilizando o conceito de intertextualidade (G.GENETTE, 1982), os conceitos-chave do modelo de Hayes e Flower, bem como as recomendações didáticas propostas por Jean-Pierre $\mathrm{CUQ}$, que incentivam os professores a mobilizarem o texto literário em atividades linguísticas nas quais se articulam as várias habilidades do francês. Os resultados atestam a contribuição que a exploração do texto literário pode oferecer como ponto de partida nas atividades de produção escrita. 
Agradecemos a todos que se dispuseram a participar desse número da Pensares em Revista, por suas importantes contribuições às reflexões sobre discurso e ensino. Esperamos que os textos aqui reunidos reverberem em muitas outras pesquisas, práticas e políticas.

\section{Sobre as organizadoras}

\section{Andréa Rodrigues}

Andréa Rodrigues é Doutora em Letras pela PUC-Rio (2001), com estágio de doutorado na École des Hautes Études en Sciences Sociales (França,1997) e Pós-Doutorado no Programa de PósGraduação em Memória Social da UNIRIO (2013). Fez Mestrado em Linguística (UFRJ, 1993) e Graduação em Letras (UFF, 1987). É professora da Graduação em Letras, do Programa de PósGraduação em Letras e Linguística (PPLIN) e do Mestrado Profissional em Letras (PROFLETRAS) da Faculdade de Formação de Professores da Universidade do Estado do Rio de Janeiro (FFPUERJ). Líder do grupo de pesquisa Núcleo de Estudos em Língua e Discurso (NELID). Atualmente, coordena a área de estudos linguísticos do PPLIN.

\section{Maristela Cury Sarian}

É graduada em Letras-Tradutor e Mestre em Estudos Linguísticos pela UNESP/São José do Rio Preto. Doutora em Linguística pela UNICAMP, é professora da Universidade do Estado de Mato Grosso (UNEMAT) Carlos Alberto Reyes Maldonado. Na gestão, atua como Coordenadora do Programa de Mestrado Profissional em Letras - PROFLETRAS ofertado na Unidade Cáceres. Como destaque na pesquisa, coordena, com Claudia Regina Castellanos Pfeiffer (LABEURB/UNICAMP) e Ana Cláudia Fernandes Ferreira (IEL/UNICAMP), a Linha 1 - História das Ideias Linguísticas - do GTAD da ANPOLL. Tem experiência na área de Letras, com ênfase em Linguística Língua Portuguesa e Estudos da Tradução.

\section{Rívia Silveira Fonseca}

Licenciada em Letras - Português/Grego (1998), Mestra em História Social (2002) pela Universidade Federal Fluminense - UFF e Doutora em Linguística (2009) pela Universidade Estadual de Campinas - UNICAMP. Atualmente, é Professora Associada I, na área de língua e literatura latina, e Chefe do Departamento de Letras e Comunicação - DLC da Universidade Federal Rural do Rio de Janeiro - UFRRJ. Faz parte do corpo docente do PROFLETRAS e desenvolve pesquisas na área dos Estudos da Linguagem, com ênfase em Teoria e Análise Linguística, Estudos do Discurso e Ensino de Línguas. 